\title{
Proximal Left Anterior Descending Artery
}

National Cancer Institute

\section{Source}

National Cancer Institute. Proximal Left Anterior Descending Artery. NCI Thesaurus.

Code C102336.

The section of the left anterior descending coronary artery that arises from the left main coronary artery and extends to the first diagonal branch. 